Article

\title{
A Proposed Simultaneous Calculation Method for Flood by River Water, Inland Flood, and Storm Surge at Tidal Rivers of Metropolitan Cities: A Case Study of Katabira River in Japan
}

\author{
Naoki Koyama ${ }^{1, *}$ and Tadashi Yamada ${ }^{2}$ \\ 1 Civil, Human and Environmental Engineering Course, Graduate School of Science and Engineering, \\ Chuo University, 1-13-27, Kasuga, Bunkyo-ku, Tokyo 112-8551, Japan \\ 2 Department of Civil and Environmental Engineering, Faculty of Science and Engineering, Chuo University, \\ 1-13-27, Kasuga, Bunkyo-ku, Tokyo 112-8551, Japan; yamada@civil.chuo-u.ac.jp \\ * Correspondence: koyama@civil.chuo-u.ac.jp; Tel.: +81-3-3817-1805
}

Received: 6 May 2020; Accepted: 18 June 2020; Published: 22 June 2020

\begin{abstract}
All metropolitan cities in Japan are located in low-lying areas that surround ports. Accordingly, significant floods that occur in these cities will trigger the simultaneous occurrence of flooding by river water and inland flooding. However, existing studies have focused on the impact of flooding by river water, inland flooding, and high tide in tidal rivers, and disaster mitigation measures focused on detailed flooding processes in such flooding areas have not been conducted thus far. This study focused on a tidal river, i.e., Katabira River of Yokohama city, one of Japan's metropolitan cities, to construct a simultaneous occurrence model of flooding by river water and inland flooding, including the impact of a high tide. Numerical analysis was conducted using this model, and the results show that the flooded area significantly changed from 0.004 to $0.149 \mathrm{~km}^{2}$ according to the tide level of the estuary. Moreover, by simultaneously solving the calculation of flooding by river water and inland flooding, we found that there was a difference of $50 \mathrm{~min}$ between the occurrences of these floods. Therefore, we found that there is a possibility that, if evacuation is not conducted at the time of occurrence of inland flooding, evacuation during subsequent river-water flooding may not be possible. Based on these results, our proposed method was found to be useful for tidal rivers of metropolitan cities.
\end{abstract}

Keywords: simultaneous calculation method; flood by river water; inland flood; storm surge; tidal river; mitigation measures; inundation; metropolitan Japanese cities

\section{Introduction}

Flooding is one of the most frequently occurring natural disasters and impacts many people every year in the world [1]. Large-scale flooding can significantly impact local societies and their economies [1,2]. For example, economic damage from flooding in the United States has cost $\$ 260$ billion (approximately $¥ 28$ trillion) per year from 1980 to 2013 [3]. Similarly, between 1970 and 2008, floods caused at least 87 billion euros (approximately $¥ 10.4$ trillion) in economic losses in Europe [4]. In Japan, the cost of damage from flooding between 1993 and 2002 was approximately $¥ 2.4$ trillion. This amount can be broken down into approximately $¥ 1.1$ trillion damage from inland flooding and roughly $¥ 1.3$ trillion from river-water flooding [5]. If it is limited to the Tokyo Metropolitan area as the largest city, the damage cost of inland flooding accounts for approximately $80 \%$ of the total [5]. Based on these data, it is clear that inland flooding causes significant economic damage in Japan. Moreover, all large cities in Japan, in which the country's population is concentrated (Tokyo, Yokohama, Osaka, Fukuoka, Nagoya, 
etc.), are all located in low-lying areas that surround ports [5]. Japan's land can be broadly categorized into mountainous areas, hilly areas, plateau, low-lying areas, and inland water areas. When these area ratios are compared, mountainous and hilly areas represent roughly $70 \%$; the population and properties are concentrated on plateau and low-lying areas that account for the remaining 30\%. For this reason, Japan's land is susceptible to receive inland flooding and high-tide damage. So-called urban flooding, which occurs in cities, has been occurring globally in recent years [6,7], and rapid urbanization is impacting the scale and frequency of such flooding [8-12]. Due to the progression of urbanization, rainwater that used to either seep into the ground or stagnated on the ground surface has started flowing directly downstream as surface water, thus increasing flooding damage in low-lying areas. Extreme changes in meteorological phenomena due to climate change are considered a global issue and are increasing the danger within cities [10-14]. In addition, climate change will raise sea levels and increase the risk of storm surges in coastal areas $[15,16]$. In addition, short torrential downpours known as guerrilla rainstorms are becoming frequent in Japanese cities. Specifically, the review of long-term changes in annual rainfall over time in Japan indicates a tendency toward increases in heavy rain, with more than 50 or $80 \mathrm{~mm}$ of hourly rainfall being observed [17]. Tropical cyclone activity is also increasing; it is said that high tides caused by the attacks of super typhoons will cause significant flood damages at Osaka Bay surrounding Osaka City, at Ise Bay surrounding Nagoya, and at Tokyo Bay surrounding Tokyo [2]. Based on the above factors, to respond to flood damage that may occur in the future in cities, it is necessary to shift to flood damage countermeasures that also consider the increase in external forces such as typhoons due to climate change. In the case of cities, rainwater is discharged into rivers via sewers. However, when heavy rainfall exceeds the external force envisaged by the design, river-water flooding occurs when the retention capacity of a river is exceeded, and inland flooding occurs when the discharge capacity of sewers is exceeded. A city is protected from flooding by these two systems working in balance. To accurately calculate/predict urban flooding, a model that can simultaneously calculate/analyze river-water flooding and inland flooding is needed. Furthermore, as discussed above, metropolitan cities in Japan are located in the places surrounding ports. Thus, there is a situation where the water level at the estuary rises due to storm surges and water flowing upstream, rendering the river unable to discharge its water into the sea. We must consider this kind of situation may occur $[18,19]$. Accordingly, what is necessary is a calculation method that takes the effect of a storm surge into account, in addition to river-water flooding and inland flooding.

Multiple previous studies have been conducted on creating methods that integrally calculate the flooding of sewers and river water in cities $[20,21]$. These include the method that integrally calculates river-water/inland flooding and analyzes flooding damage using differences in total rainfall and rainfall intensity [20]. In addition, a proposed model enables real-time river-water/inland flooding prediction simulation for the approximately $620 \mathrm{~km}^{2}$ of 23 wards of Tokyo Metropolis [21]. In addition, previous studies have conducted numerical calculations on the effect of storm surge and wind on water levels in estuaries for coastal areas [22-25]. Pinheiro et al. simulated the effect of storm surge on river water levels [22], Oliveira, H. analyzed the effect of wind on water levels in coastal areas [23]. In addition, Ullman, D.S. et al. simulated the ocean and estuary response to storm surge and rainfall from hurricanes [24]. Cavallaro, L. et al. analyzed the effect of mobile gates on river water level during high tides and floods using numerical analysis [25]. However, no calculation method that takes the impact of a storm surge into account, in addition to river-water and inland flooding, has been proposed in previous studies.

Thus, in this paper, we propose a method that takes into account the effect of a storm surge on river-water/inland flooding. This method is applicable to large cities. We also suggest the importance of considering a storm surge by analyzing its results. The objective of this paper is to discuss disaster mitigation measures taking concrete inundation processes into account. 


\section{The Basin Area of Interest}

\subsection{Overview of Katabira River (Yokohama City)}

This paper is aimed at the Katabira River basin, which flows through Yokohama City, one of the largest cities in Japan. Yokohama Station is located at the estuary of the Katabira River, and flood damages frequently have occurred in the area around Yokohama Station, mostly due to typhoon damage [26]. The basin area of Katabira River is $57.9 \mathrm{~km}^{2}$, and the length of the main river channel is $17.3 \mathrm{~km}$. Figure 1 shows an elevation map (Figure $1 \mathrm{a}$ ) and a pipeline network map (Figure $1 \mathrm{~b}$ ) in the Katabira River basin. The estuary faces Tokyo Bay, and the tidal area is up to $4 \mathrm{~km}$ from the estuary. As shown in Figure 1b, there are different types of sewage systems within the Katabira River basin. In the upstream area, the system comprises separate sewers where the rainwater line and sewage line are separated, while, in the downstream area, the system is equipped with combined sewers where rainwater and sewage flow through the same single pipe. When viewing from the entire basin, the combined sewers are used in approximately $30 \%$ of the total area. In addition, facilities such as floodways for discharging overflowing rainwater during a flood and drainage pumping stations for controlling the flow of rivers are equipped in the basin. Figure 2a shows an aerial photo of the tidal area of Katabira River basin and Figure $2 b$ shows a photo of Katabira River (upper stream from Bridge $B$ in Figure 1a). The tidal area is a completely urbanized area and Katabira River is concrete-lined.

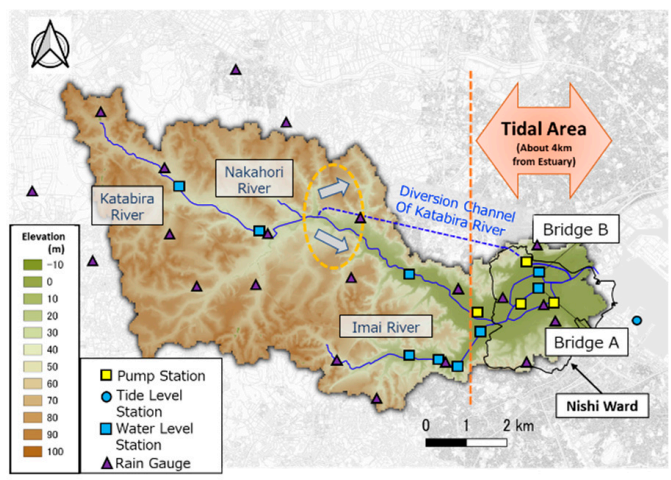

(a)

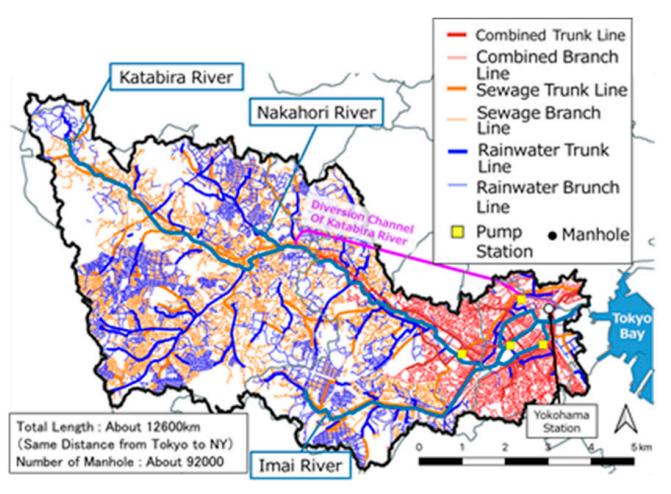

(b)

Figure 1. Overview of Katabira River basin: (a) elevation map; and (b) pipeline networks map.

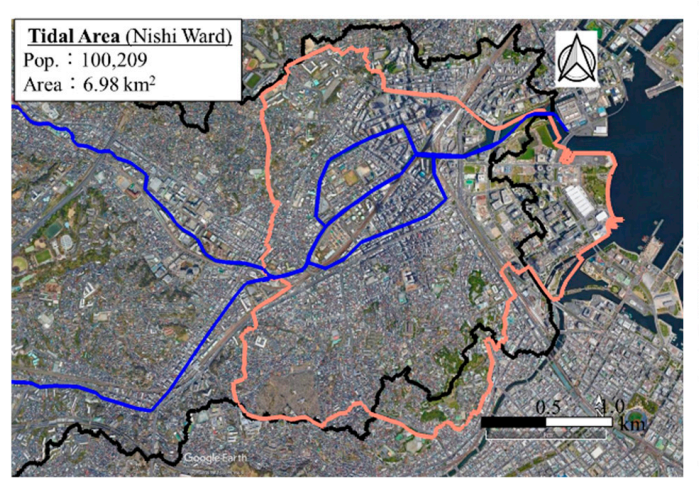

(a)

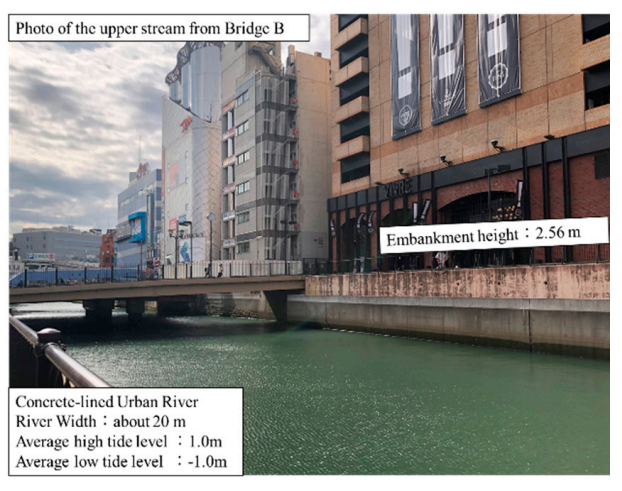

(b)

Figure 2. Overview of the tidal area: (a) aerial photo; and (b) photo of Katabira River.

\subsection{The Relationship between Weather Conditions and Increased Water Level in Katabira River}

\subsubsection{The Relationship between Total Rainfall and Maximum Water Level Deviation}

Figure 3 shows the relationship between the peak rainfall intensity and water level deviation (Figure 3a) and between the total rainfall and water level deviation Figure 3b, at Bridge A (as shown 
in Figure 1a, $2.1 \mathrm{~km}$ upstream from the estuary) in the 1205 rainfall events that occurred for 11 years between 2008 and 2018. Here, water level deviation indicates the value obtained by subtracting the astronomical tide level at the estuary from the observed water level. Astronomical tide level is the predicted tide level and is calculated based on the tide levels observed in the past, and this tide level is not influenced by the weather. The maximum tide level deviation indicates the value where the tidal level deviation became the highest during a rainfall event. At the water level observation station of interest, it can be concluded that there is less correlation between peak rainfall intensity and water level deviation (Figure 3a), while there is correlation between the total rainfall and water level deviation (Figure 3b). Moreover, many of the events with maximum water level deviations are rainfall events caused by typhoons. The Katabira River basin is relatively large as an urban river, approximately $60 \mathrm{~km}^{2}$; thus, it is considered to be more susceptible to typhoon rainfall than short-term concentrated rainfall such as heavy guerrilla rainfall. Moreover, it is considered that the water level deviation becomes large due to the storm surge when a typhoon makes landfall because the Katabira River basin is located at the estuary and influenced by the tide level. However, there are variations in the maximum water level deviations of events with similar total rainfalls.

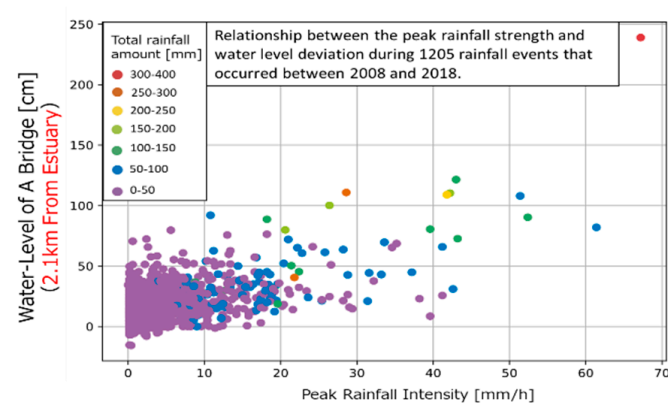

(a)

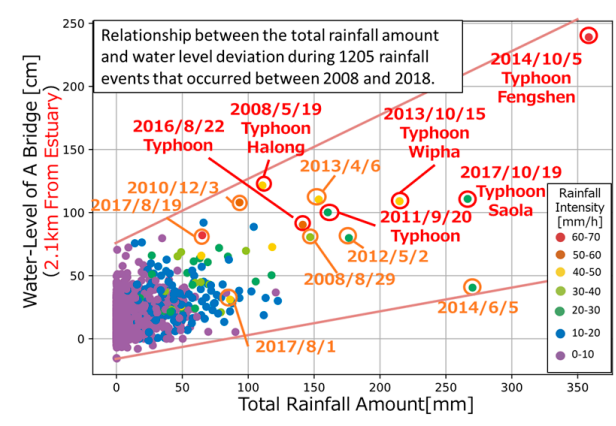

(b)

Figure 3. (a) Relationship between peak rainfall intensity and water level deviation; and (b) relationship between total rainfall and water level deviation.

\subsubsection{The Relationship between Water Level Deviation and Weather Conditions}

In Section 2.2.1, it is found that the possibility that weather conditions may influence the variations in water level deviations. To validate this possibility, Figure 4 presents the relationship between water level deviation and weather conditions at the time when Typhoon Phanfone made landfall in 2014, showing that the total rainfall and the maximum water level deviation were both significant. The observed value of tide level deviation changes (increases) with changes in atmospheric pressure, wind direction, and wind speed. The value of tide level deviation (the value obtained by subtracting astronomical tide level from the observed water level) showed an increase in water level due to rainfall. While there were few changes in either atmospheric pressure or wind speed during this rainfall event, the water level increased the most at the time when the wind direction changed to a southeast direction. For this reason, it is clear that accurate simulation is not possible without including the tide level at the estuary in calculation conditions. Furthermore, while the water level was not affected when rain with a rainfall intensity of $10 \mathrm{~mm} / \mathrm{h}$ continued to fall, the water level rose when the rainfall intensity exceeded $30 \mathrm{~mm} / \mathrm{h}$.

In Section 2.2.1, it is noted that water level deviation can differ even though the total rainfall is approximately the same. Therefore, the relationship between water level and weather conditions for two rainfall events whose total rainfall was approximately $270 \mathrm{~mm}$ (Typhoon Saola on 19 October 2017 and a heavy rain event on 5 June 2014) were compared. Figure 5 organizes the water level deviations and weather conditions of the two events. Figure 5 a shows the water level deviation during the typhoon rainfall event. It is clear that atmospheric pressure, wind direction, and wind speed affected impacts. While rain with a strength of approximately $40 \mathrm{~mm} / \mathrm{h}$ fell, it did not influence the 
water level deviation as this occurred during low tide. Moreover, the atmospheric pressure decreased approximately $50 \mathrm{hPa}$ once the typhoon made landfall. Considering a 1-hPa decrease in atmospheric pressure causes an approximately 1-cm increase in water level due to the static sucking effect [27], an approximately $50-\mathrm{cm}$ increase in tide level is inferred to have occurred due to a reduction in atmospheric pressure. Furthermore, the wind speed increased as the atmospheric pressure decreased and the wind direction changed to southeast, hitting the estuary. Thus, it can be concluded that the tide level increased approximately $100 \mathrm{~cm}$ due to the effects of atmospheric pressure, wind direction, and wind speed. In addition, the arrival of the typhoon coincided with full tide, further increasing the water level deviation. Next, we present the case of a rainfall event caused by heavy rain (Figure 5b). As this was not a typhoon-related rainfall event, there was hardly any change in atmospheric pressure or wind, and the water level changed only due to the amount of rainfall. Since this event involved rain continuing over a long period of time, it is inferred that it did not cause a significant increase in water level. Accordingly, it was interpreted that the water level increase of a river at its estuary was significantly influenced by weather conditions, atmospheric pressure, wind direction, wind speed, and the timing of tidal changes. In addition to precipitation, these factors play a role in whether flooding is triggered.

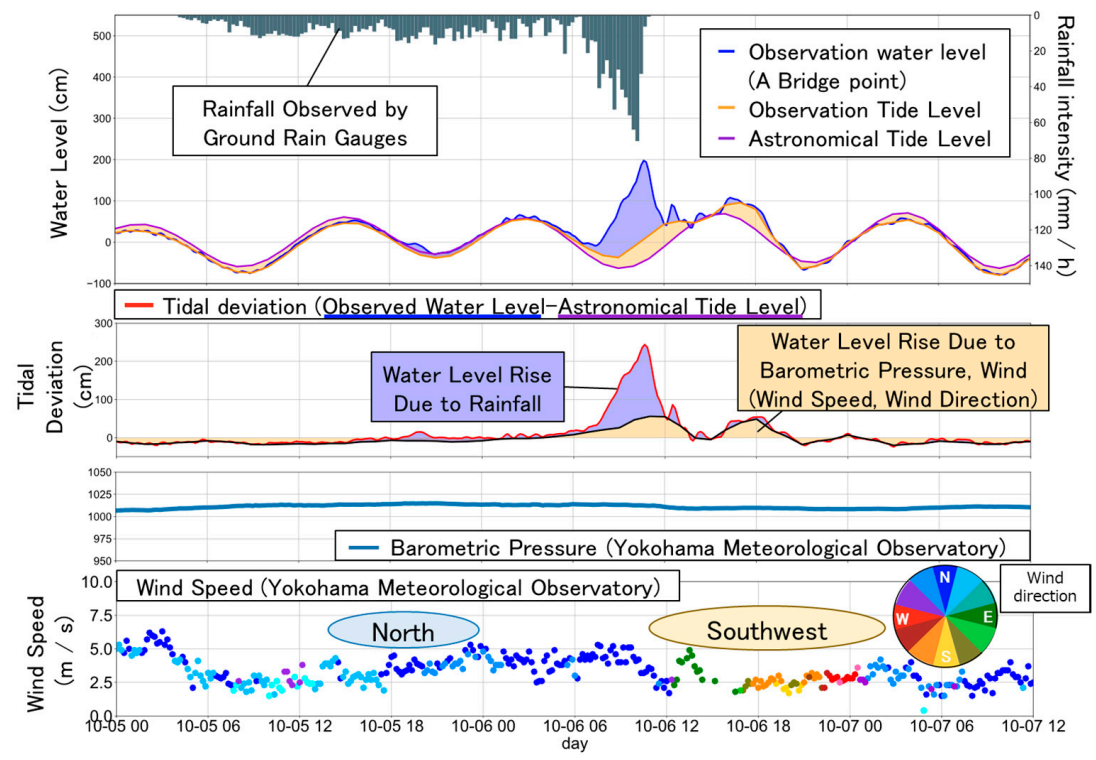

Figure 4. The relationship between water level deviation and weather conditions (at the time of Typhoon Phanfone making landfall in 2014).

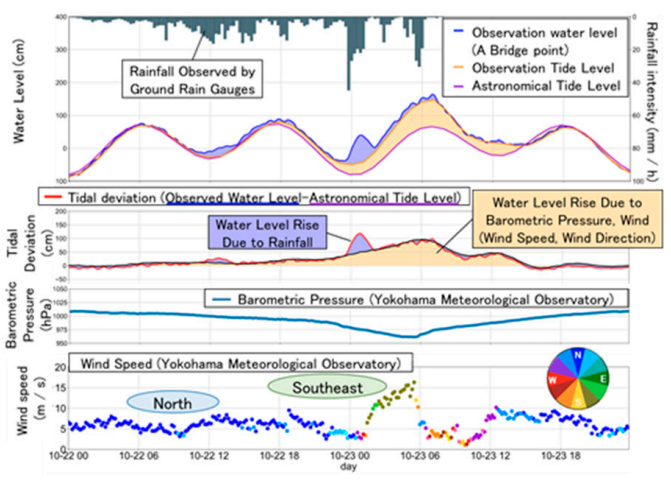

(a)

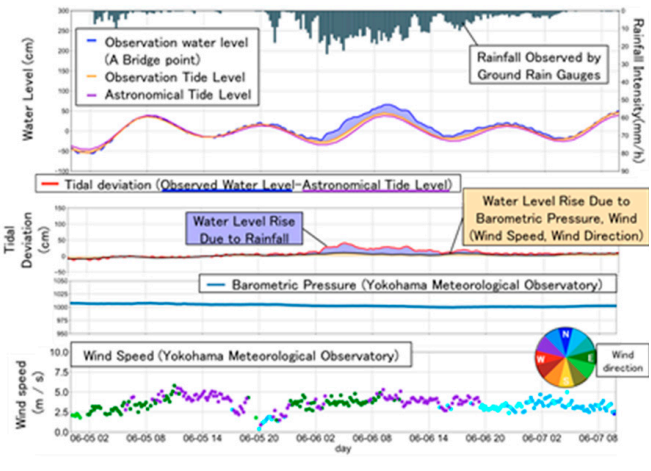

(b)

Figure 5. The relationship between water level deviation and weather conditions: (a) at the time of Typhoon Saola making landfall in 2017; and (b) during a heavy rain event in 2014. 


\section{Creating A River-Water/Inland Water Simultaneous Analysis Model that Considers High Tide}

\subsection{Structure of the Simultaneous Analysis Model}

In this study, a calculation model was built using NILIM2.0 software, programmed by the National Institute for Land and Infrastructure Management (March 2012 released) [28]. Figure 6 shows the conceptual diagram of the river-water/inland water simultaneous analysis model. The model calculated the process from rainfall outflow to flooding by dividing it into five sections and estimated the inundation height and flood locations by combining the calculation results of these five sections, where (I) is the process of rainfall flowing into the river, calculated using the synthesized rational formula, and (II) is the process of the outflowing river water flowing downstream, calculated using the one-dimensional unsteady flow analysis. For these factors, the outflow obtained through rainfall-runoff calculation was given as the boundary condition to the upper reach, and the tide level that took the influence of high tide into account was given as the boundary condition to the downstream end. Furthermore, (III) is the process of the rainwater being collected through manholes, calculated using the kinematic wave method, and (IV) is the sewage tracking calculation that obtained the flow of water collected through the manholes inside the sewers and was calculated using the dynamic wave method. (III) and (IV) were calculated only for the downstream basin, where there was an effect of high tide. (V) is the process of the expansion of inland flooding caused by overflow from manholes and river-water flooding caused by overflow from levees; a horizontal two-dimensional unsteady flow equation was used for the ground surface flooding calculation necessary to calculate it. The respective calculation methods for the above-noted conditions are provided below.

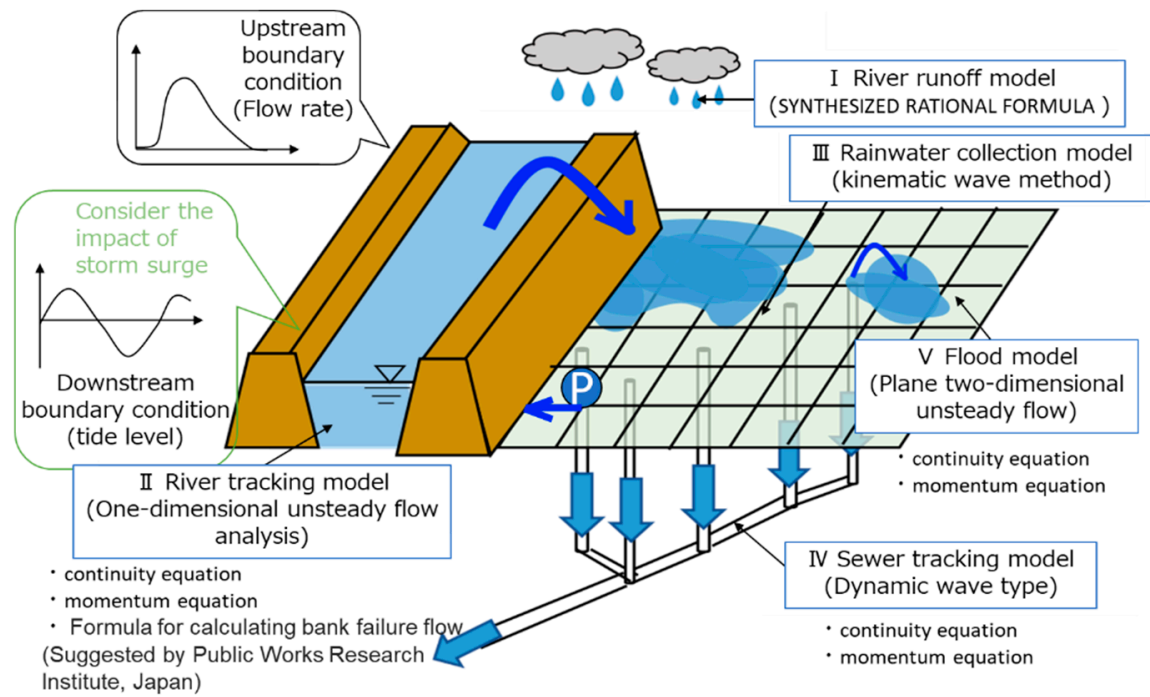

Figure 6. Conceptual diagram of simultaneous analysis model of internal and external water.

\subsubsection{Calculation of Outflow into the River (I)}

To calculate outflow into the river, the synthesized rational formula, commonly used for the planning of small- and medium-sized rivers or sewers was used; this was because the basin area under study was only roughly $60 \mathrm{~km}^{2}$ [29]. The synthesized rational formula is shown in Equation (1):

$$
q_{n}(t)=r_{n}^{a v e} v\left[\begin{array}{l}
\left\{\left(t-t_{n}\right) H\left[t-t_{n}\right]-\left(t-\left(t_{n}+t_{r}\right)\right) H\left[t-\left(t_{n}+t_{r}\right)\right]\right\}- \\
\left\{\begin{array}{l}
\left(t-t_{n}-\frac{x}{v}\right) H\left[t-t_{n}-\frac{x}{v}\right]- \\
\left(t-\left(t_{n}+t_{r}\right)-\frac{x}{v}\right) H\left[t-\left(t_{n}+t_{r}-\frac{x}{v}\right)\right]
\end{array}\right\}
\end{array}\right]
$$


However, it is

$$
H(x-a)=\left\{\begin{array}{l}
1(x>a) \\
0(x<a)
\end{array}\right.
$$

Here, $q$ is the runoff ratio $[\mathrm{mm} / \mathrm{h}], n$ is the calculation time, $x$ is the slope length $[\mathrm{m}], r_{n}^{\text {ave }}$ is the average rainfall amount $[\mathrm{mm} / \mathrm{h}], t_{n}$ is the start time of rainfall, $t_{r}$ is the duration of rainfall, $v$ is the cross-sectional average flow velocity $[\mathrm{m} / \mathrm{s}], x / v$ is the flood concentration time, and $H$ is the Heaviside step function.

\subsubsection{River Channel Tracking Calculation (II)}

The one-dimensional unsteady flow was used for river channel tracking calculation. Equation (3) and Equation (4) represent continuous and momentum equations, respectively, which were the fundamental equations used in this calculation.

$$
\begin{gathered}
\frac{\partial A}{\partial t}+\frac{\partial Q}{\partial x}=q \\
A \frac{\partial Q}{\partial t}+Q^{2} \frac{\partial \beta}{\partial x}-2 \beta Q \frac{\partial A}{\partial x}-\frac{\beta Q^{2}}{A} \frac{\partial A}{\partial x}+g A^{2} \frac{\partial H}{\partial x}+\frac{A}{\rho} \tau=0
\end{gathered}
$$

However, it is:

$$
\tau=\rho g A \frac{Q|Q|}{\left(\sum_{i=1} \frac{A_{i}}{n_{i}} R_{i}^{\frac{2}{3}}\right)^{2}}
$$

Here, $A$ is the water conduction cross-sectional area, $R$ is the hydraulic mean depth, $Q$ is the flow amount $\left[\mathrm{m}^{3} / \mathrm{s}\right], q$ is the horizontal inflow per unit width $\left[\mathrm{m}^{2} / \mathrm{s}\right], n$ is the roughness coefficient of Manning, $h$ is the water depth, $\beta$ is the synthesized coefficient of the high and low water channels, $g$ is the gravitational acceleration, $\rho$ is water density, $x$ is the distance $[\mathrm{m}]$, and $t$ is time [s]. To calculate levee overflow amount $\mathrm{Qb}$, the levee overflow amount equation [30] proposed by the Public Works Research Institute was used.

When $h_{2} / h_{1}<2 / 3$ :

$$
\frac{\partial A}{\partial t}+\frac{\partial Q}{\partial x}=q
$$

When $h_{2} / h_{1} \geqq 2 / 3$ :

$$
P={\frac{r_{d d}}{h}}_{1}
$$

When $|P| \leqq 0.84$ and $P>0$ :

$$
Q_{b}=(0.6-0.3 \cdot P) \cdot\left(h_{2}+r_{d d}\right) \cdot \sqrt{2 g\left(h_{1}-h_{2}\right)}
$$

When $|P| \leqq 0.84$ and $P \leqq 0$ :

$$
q=(0.6-0.4 \cdot P) h_{2} \cdot \sqrt{2 g\left(h_{1}-h_{2}\right)}
$$

When $|P|>0.84$ :

$$
q=0.91 \cdot h_{2} \cdot \sqrt{2 g\left(h_{1}-h_{2}\right)}
$$

Figure 7 shows a conceptual diagram of the equation of the above-noted levee breach amount. $h_{1}$ and $h_{2}$ are the water depths of the inland and outland areas of the embankment, respectively, as measured from the embankment height. $P$ is the ratio of levee height $r_{d d}$ to the river water level from the levee height. 


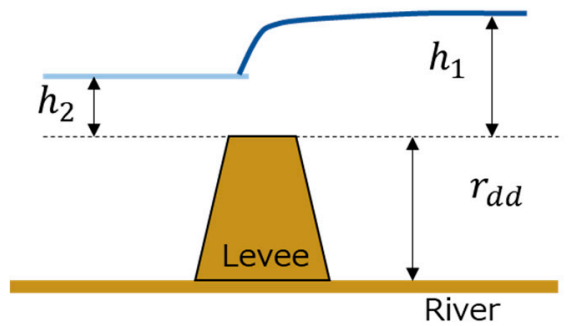

Figure 7. The conceptual diagram for deriving the levee breach degree.

\subsubsection{Rainwater Collection Calculation (III)}

The kinematic wave method was used to calculate rainwater collection. The water collection area allocated to each manhole was set by substituting the water collection area of a manhole with a rectangular slope. Furthermore, by setting the equivalent roughness coefficient and slope inclination at the water collection area based on the land usage situation there, the surface flow amount was calculated. The fundamental equations of the kinematic wave method can be found below.

$$
\begin{gathered}
\frac{\partial h}{\partial t}+\frac{\partial q}{\partial x}=r \\
h=K \times q^{p}
\end{gathered}
$$

Here, $h$ is the depth of water on the slope, $q$ is the flow per unit width of the slope, $r$ is the effective rainfall strength, $R$ the hydraulic mean depth, and $K$ and $p$ are the constants. The values defined by TOYOKUNI et al. [31] (Table 1 ) were used as the parameters of $K$ and $p$.

Table 1. Equivalent roughness coefficient and slope inclination corresponding to the land usage category.

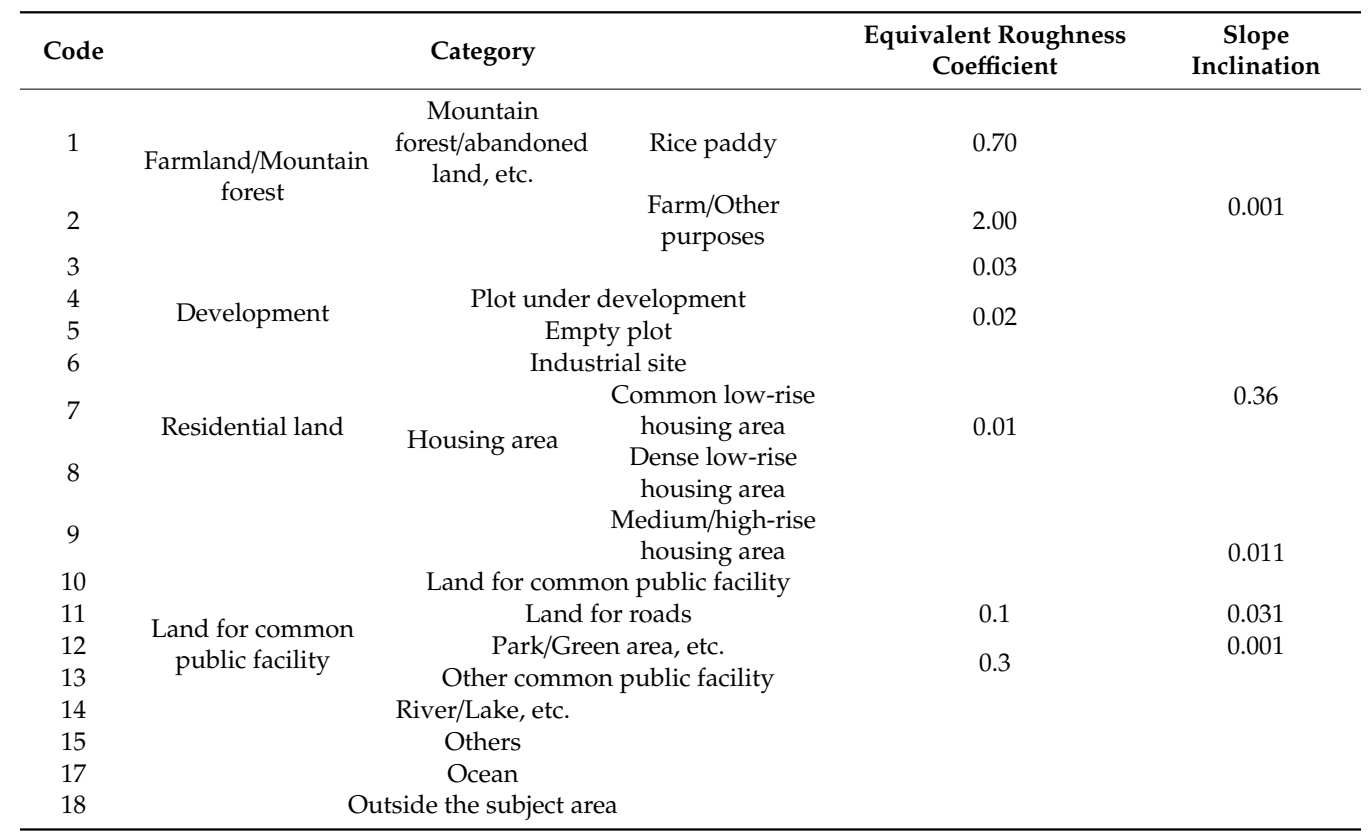

\subsubsection{Sewer Pipeline Calculation (IV)}

The diffusion wave equation was used to calculate the sewer line. The continuous equation, which is the fundamental operation in Equation (13), depends on the state inside the pipeline, and is either open water channel flow or pressure flow, as shown in Equation (14), while Equation (15) is the momentum equation.

$$
\frac{\partial A}{\partial t}+\frac{\partial Q}{\partial x}=q_{i n}
$$




$$
\begin{gathered}
\frac{\partial h}{\partial x}+\frac{C^{2}}{g} \frac{\partial u}{\partial x}=\frac{C^{2}}{q A_{0}} q_{i n} \\
\frac{\partial h}{\partial x}=S_{0}-S_{f}=S_{0}-\left(\frac{n^{2}}{R^{\frac{4}{3}}}+\frac{k}{2 g L}\right) \frac{Q^{2}}{A^{2}}
\end{gathered}
$$

However, it is;

$$
C=\left(g \frac{\sin \varphi}{N} \frac{A_{0}}{A_{L}}\right)^{\frac{1}{2}}
$$

Here, $A$ is the water conduction cross-sectional area, $\theta$ the flow amount, $q_{\text {in }}$ is the horizontal inflow amount, $n$ is the roughness coefficient, $R$ the hydraulic mean depth, $S_{0}$ is the water channel floor inclination, $h$ is the water depth, $A_{0}$ is the pipeline cross-sectional area, $A_{l}$ is the pipeline cross-sectional area, $L$ is the pipeline length, $\varphi$ the connection angle, $N$ is the number of attached pipes, $C$ is the pressure wave velocity, and $S_{f}$ is the friction loss inclination and $k$ the local loss factor.

\subsubsection{Ground Surface Flooding Calculation (V)}

Two-dimensional unsteady flow was used to calculate ground surface flooding. The same equation was employed for both river water flooding and inland flooding. Equation (17) is the continuous equation and Equation (18) is the momentum equation, which constitute the fundamental equations used.

$$
\begin{gathered}
\frac{\partial h}{\partial t}+\frac{\partial M}{\partial x}+\frac{\partial N}{\partial y}=0 \\
\frac{\partial M}{\partial t}+\frac{\partial(u M)}{\partial x}+\frac{\partial(v M)}{\partial y}+g h \frac{\partial H}{\partial x}+\frac{1}{\rho} \tau_{x}=0 \\
\frac{\partial N}{\partial t}+\frac{\partial(u N)}{\partial x}+\frac{\partial(v N)}{\partial y}+g h \frac{\partial H}{\partial y}+\frac{1}{\rho} \tau_{y}=0 \\
\tau_{x}=\frac{\rho g n^{2} \bar{u} \sqrt{\left(u^{2}+v^{2}\right)}}{h^{\frac{1}{3}}} \\
\tau_{x}=\frac{\rho g n^{2} \bar{v} \sqrt{\left(u^{2}+v^{2}\right)}}{h^{\frac{1}{3}}}
\end{gathered}
$$

Here, $H$ is the water level, $h$ is the depth of inundation, $u$ and $v$ are the flow speed in the $x$ and $y$ directions, $g$ is the gravitational acceleration, $\rho$ is the water density, $M$ and $N$ are the flow flux of the $x$ and $y$ directions $(M=u h, N=v h), \tau_{x}(b), \tau_{y}(b)$ the shearing force in the $x$ and $y$ directions, $\bar{u}$ and $\bar{v}$ are the average of the flow speed at the current time and previous time and $n$ is the bottom roughness coefficient $\left(n_{0}\right.$ is the synthesized equivalent roughness coefficient, and $\theta$ is the building occupancy (\%). Moreover, Equation (20) was used for bottom roughness and Equation (21) was used for the bottom roughness coefficient of meshes other than buildings. [28]

$$
\begin{gathered}
n^{2}=n_{0}^{2}+0.020 \times \frac{\theta}{100-\theta} \times h^{\frac{4}{3}} \\
n_{0}^{2}=\frac{\left(n_{1}^{2} A_{1}+n_{2}^{2} A_{2}+n_{3}^{2} A_{3}\right)}{\left(A_{1}+A_{2}+A_{3}\right)}
\end{gathered}
$$

Here, the calculation was conducted with $n$ as the bottom roughness coefficient, $n$ as the bottom roughness coefficient of the areas other than buildings, $\theta$ as the building occupancy (\%), $h$ as the depth of inundation (m), $A_{1}$ as the farm area, $A_{2}$ as the road area, $A_{3}$ as the area other than the farm or road, $n_{1}$ as the farm roughness coefficient $(=0.060), n_{2}$ as the road roughness coefficient $(=0.047)$, and $n_{3}$ as the roughness coefficient of the area other than farms or roads $(=0.050)$ [28]. 


\subsection{Verifying the Accuracy of the Constructed Model}

The calculations of runoff into the river, river water flooding and inland flooding were individually conducted in order to examine the accuracy of the river water/inland simultaneous flooding analysis model that takes high tide into account

\subsubsection{Verifying the Accuracy of the Calculation Method of Runoff into the River}

The section that is upstream from the confluence of the main stream of the Katabira River and its branches was divided into four catchments in order to calculate the runoff into the river, and the result of the calculation was examined. However, as downstream from the confluence of the Katabira

River and the Imai River is the area where combined sewers are used and rainwater is discharged through them, calculation of the runoff into the river was not conducted for this area and rainwater collection calculation and sewer pipeline calculations were conducted instead. The division of catchments is shown in Figure 8, with the area and runoff ratio of each catchment shown in Table 2. The flood concentration time was uniformly set to $1 \mathrm{~h}$. The operational standard established by Kanagawa prefecture, which has been in use since 2004, was employed for the branching point of the Katabira River and its floodway, and the ratio of the runoff amount between the diversion channel and main stream was set at $8: 2$ until the flow through the floodway reached $260 \mathrm{~m}^{3} / \mathrm{s}$. After that point, every runoff was set to flow into the main stream. When conducting the river channel calculation, the flow amount was given as the boundary condition to the upstream end of the Imai River and upstream from the confluence of the Imai and Katabira Rivers (the point indicated with a red star in Figure 8), and the tide level was given as the boundary condition to the downstream end of the Katabira River. The roughness coefficient $n$ was set at $n=0.034$ uniformly throughout the area [30]. A verification of the accuracy of the river channel runoff calculation was conducted by comparing the real measurement of the water level and the calculation result. The rainfall event used for the calculation was typhoon Saola from 2017 at the point of its arrival; the two days between 0:00 on October 27, 2017 and 24:00 on October 28, 2017 were studied. The rainfall data observed by the ground rain gauge were used for the examination. The accumulated rainfall during this event was $193 \mathrm{~mm}$. Figure 9 shows the comparison of the calculation result and measurement. The measurement was reproduced at Bridge A, located $1.8 \mathrm{~km}$ from the river mouth, and at Bridge B, located $1.6 \mathrm{~km}$ from the river mouth (see Figure 8).

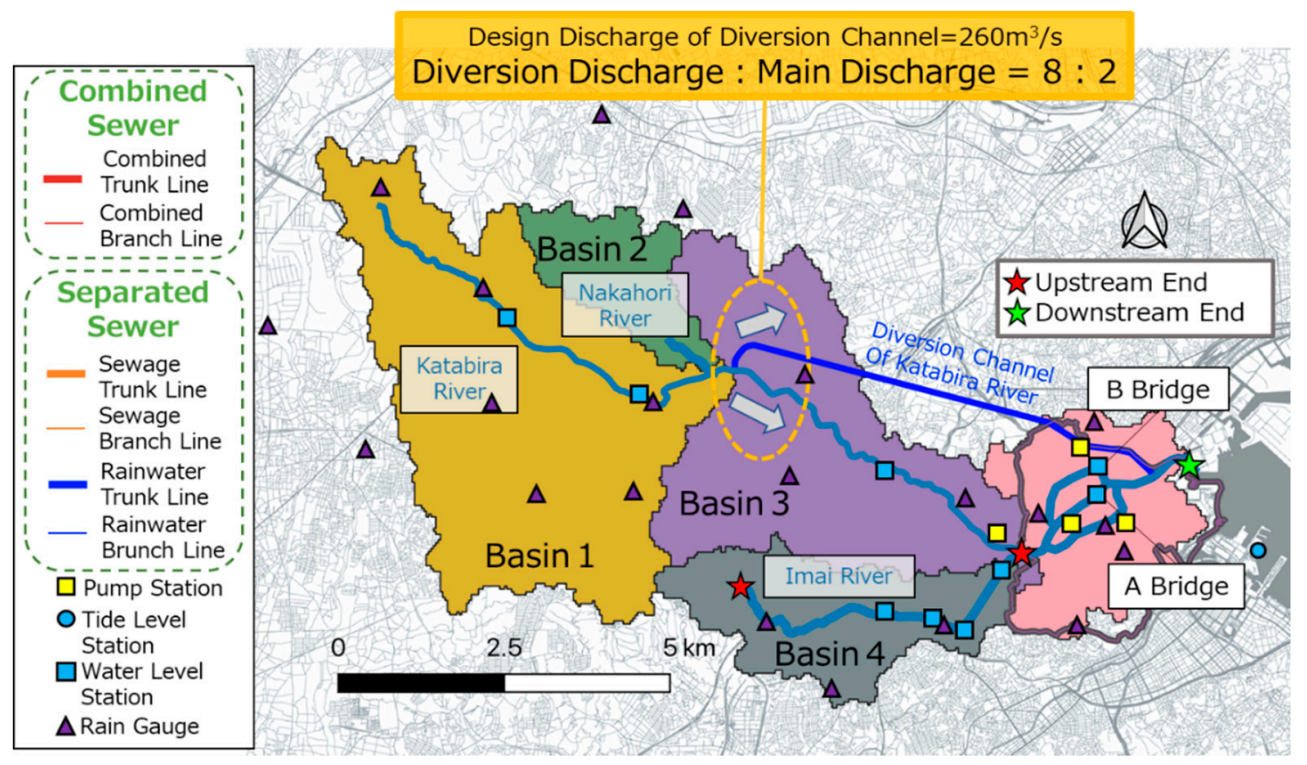

Figure 8. Catchment division diagram. 
Table 2. Area and runoff ratio of catchments.

\begin{tabular}{ccc}
\hline Basin & Area $\left.\mathbf{( k m}^{\mathbf{2}}\right)$ & Runoff Ratio \\
\hline Basin 1 & 22.6 & 0.9 \\
Basin 2 & 3.4 & 0.8 \\
Basin 3 & 116.1 & 0.9 \\
Basin 4 & 7.5 & 0.8 \\
\hline
\end{tabular}

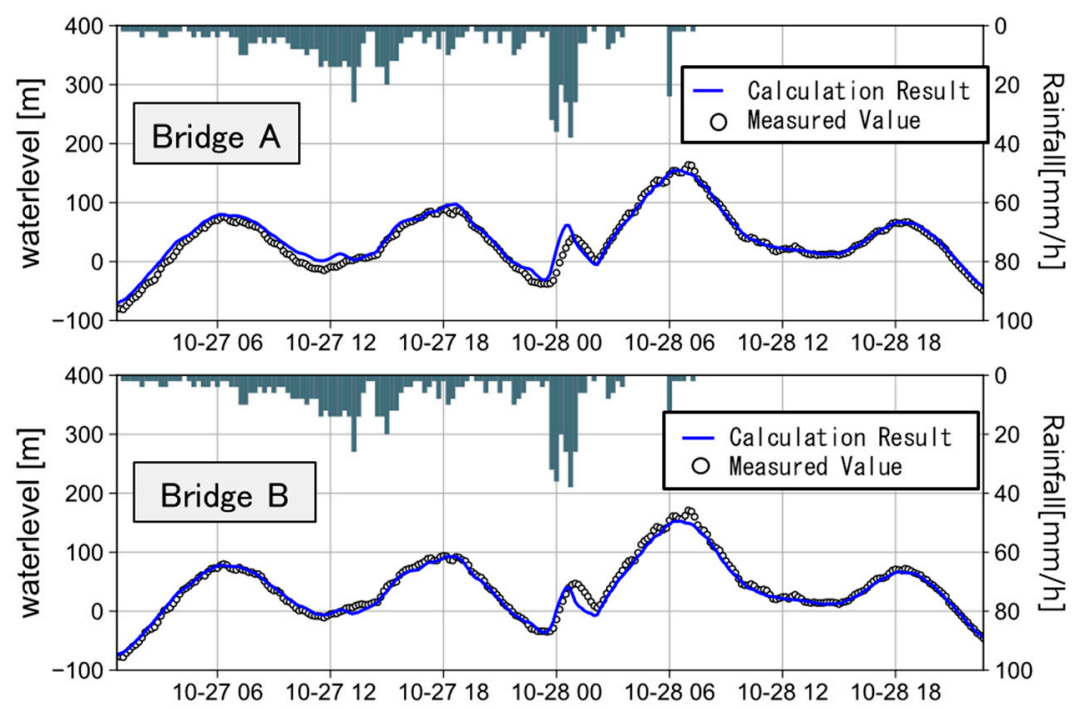

Figure 9. Comparison of the calculation result of the river channel water level analysis and measurement.

\subsubsection{Accuracy Examination of the River Water Flooding Calculation Method}

While it is desirable to compare the calculation result of this method and the real measurement data of flooding from the past in order to verify the accuracy of the river water flooding calculation method, in reality it is common that the inundation area or inundation depth are not studied unless large-scale flooding occurs. Thus, in this accuracy verification, the calculation was conducted by using the same condition and rainfall data used for producing the river water hazard map of the Katabira River, and the verification was conducted by comparing the calculation result, inundation area and inundation depth shown in the hazard map. The rainfall event used for the calculation was typhoon Rolly from 2004 at the point of its arrival, with the $11 \mathrm{~h}$ between 11:00 on October 9, 2004 and 22:00 on October 9, 2004 being studied. The rainfall data observed by the ground rain gauge was used for the examination. The cumulative rainfall of this event was $198 \mathrm{~mm}$. Moreover, the tide level at the downstream end was obtained by combining the peak of the river water level of the downstream basin and that of high tide, as this was expected to occur during the spring high tide, as was the case for the conditions on whose basis the hazard map was produced. Figure 10 shows a comparison of the river water flooding calculation result and the hazard map. Both the inundation area and inundation depth were faithfully reproduced. 


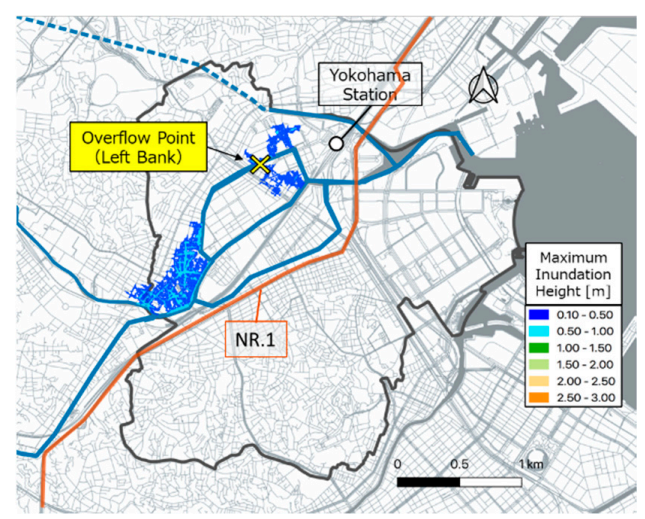

(a)

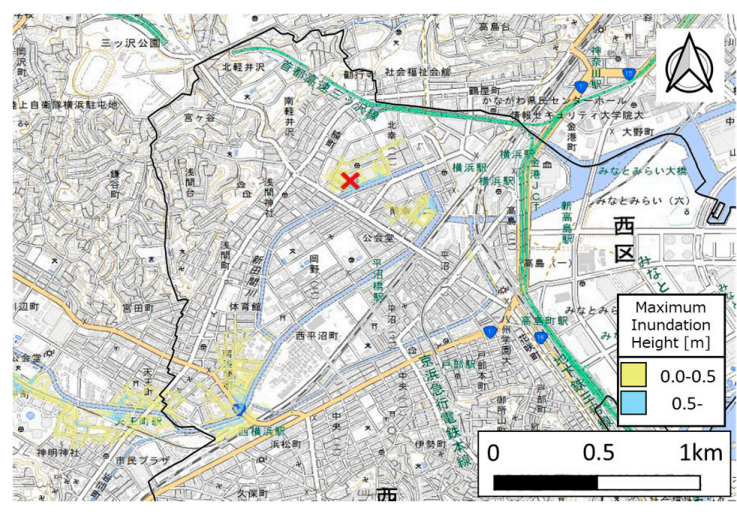

(b)

Figure 10. Comparison of the river water flooding calculation result and analysis result in the report on flooding hazard map production: (a) river water flooding analysis result; and (b) report on the flooding hazard map production.

\subsubsection{Verifying the Accuracy of the Inland Flooding Calculation Method}

It is necessary to first adjust the parameters used for the rainwater collection calculation, sewer tracking calculation and ground surface flooding calculation and then examine them in order to construct an inland flooding calculation method. The area where the inland flooding calculation method was applied is the downstream basin, which is an estuary and feature combined sewers (see Figure 11).

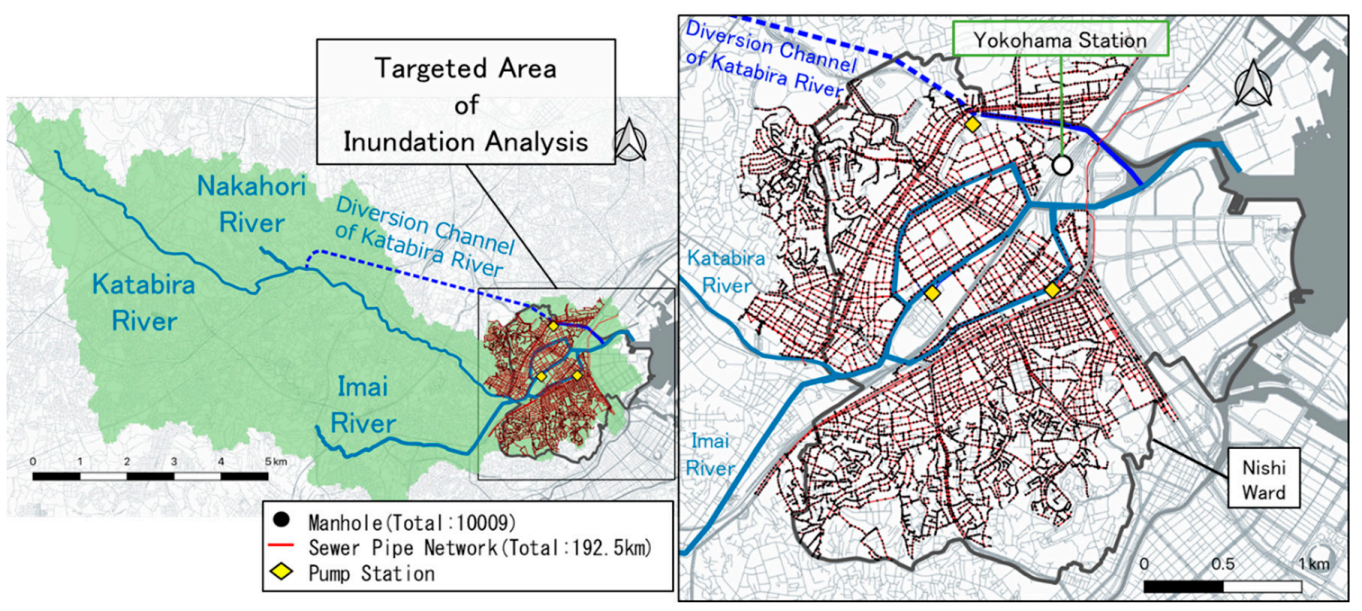

Figure 11. Subject area for calculation.

For the rainwater collection calculation, the collection area was defined by conducting a Voronoi tessellation on the subject area for each manhole of the pipeline, with equivalent roughness and slope inclinations given in order to solve using the kinematic wave method. The values of the equivalent roughness and slope inclination were set at $n i=0.01$ and $i=0.360$, respectively, in accordance with the aforementioned Table 1 . The roughness coefficient within the pipeline for the sewer tracking calculation was set to 0.013 , considering the length of approximately $192.5 \mathrm{~km}$ of pipeline and 10,009 manholes within the basin [24]. For the operation of the pump station, the operating conditions of three pump stations were considered. For the ground surface flooding calculation, the lattice size of the calculation result was set to $5 \mathrm{~m}$ mesh, and a numerical map of $5 \mathrm{~m}$ mesh was also used for the altitude [32]. Moreover, for the bottom roughness coefficient of the areas other than buildings, it was postulated that anywhere other than buildings were road, as was the case with the river water flooding analysis calculation, with 0.047 taken to hold uniformly throughout the basin area [27]. As there is no 
real measurement data that can be used for verifying the inland flooding calculation, as was the case with the river water flooding calculation, the calculation was conducted using the same conditions and rainfall data used to produce the inland water hazard map, with the examination conducted by comparing the calculation result and inundation area and the inundation depth shown in the inland water hazard map. The rainfall event used the same event as that described in Section 3.2.2. Figure 12 shows the comparison of the inland flooding calculation result and inland water hazard map. When examining the inundation situation of the area around Yokohama Station, indicated with a white dot, both the inundation area and inundation depth were mostly reproduced. However, the calculation result of the area around National Route 1 showed a deeper inundation depth than that of the inland hazard map. This was due to the fact that the inland hazard map does not represent the inundation situation of main roads. Thus, the validity of the calculation result could not be assessed.

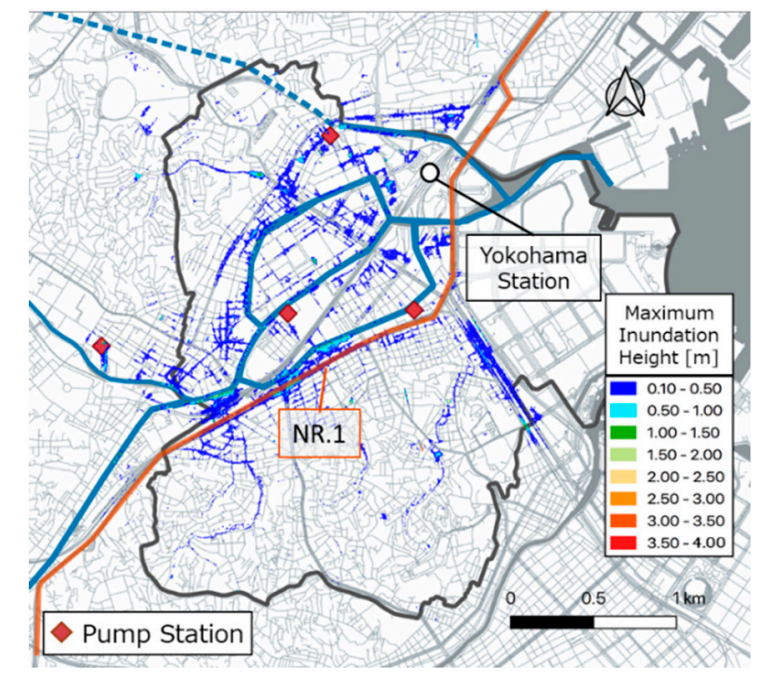

(a)

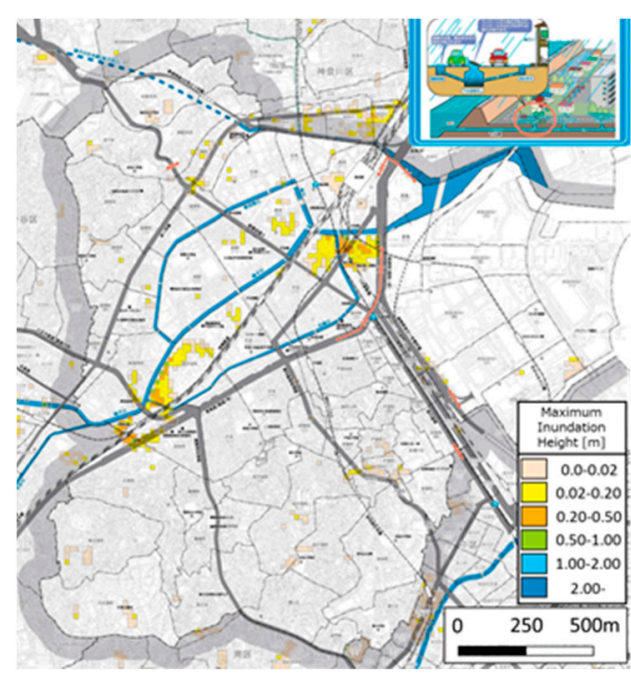

(b)

Figure 12. Comparison of inland flooding: (a) inland water analysis result; and (b) report on the inland water hazard map production.

\section{Results and Discussion}

\subsection{The Effect of High Tide on River Water Flooding}

There is a possibility that flooding from a river caused by rainfall and an increase in the tide level at the estuary occur simultaneously when a typhoon hits [33]. Anticipating such a scenario, the effect of high tide on river water flooding was analyzed. Two sets of conditions, namely when the tide level is high and when it is low were given as the boundary conditions for the downstream end. The conditions were given by postulating that the case when the tide level at the downstream end is high and that for when it is low would occur simultaneously for the peak water level of the calculation of runoff into the river at this point. The maximum anticipated tide level was set to $2.3 \mathrm{~m}$ (high astronomical tide level + storm surge), which is the maximum planned tide level, and this was given so as to be synchronized with the peak water level of the runoff. The maximum planned tide level is set by the port administration by anticipating the occurrence of storm surge during high tide in the spring tide season. The minimum tide level was given by setting it at the low tide level during the neap tide season, which is the lowest tide level throughout the year, and synchronizing it to the peak water level of the runoff. The rainfall event used the same event as that described in Section 3.2.2. Figure 13 shows the comparison of the inundation situation when the maximum anticipated high tide and flooding occurred simultaneously and the inundation situation when low tide and flooding both occurred. It was determined that when high tide occurs during full tide in the spring tide season, the effect of the downstream tide level is transmitted to the river water level, causing flooding on the 
downstream side, and that when low tide occurs during the neap tide season, the river water level is not influenced by the tide level, causing flooding on the upstream side. Moreover, from the fact that the inundation area significantly differs depending on the height of the tide level, it was found not to be possible to accurately anticipate the flooding situation of a tidal river if the effect of the high tide is not included.

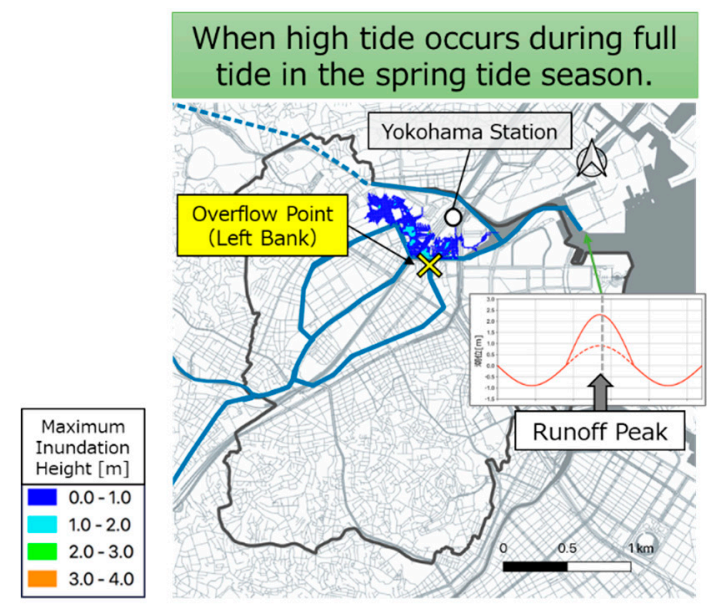

(a)

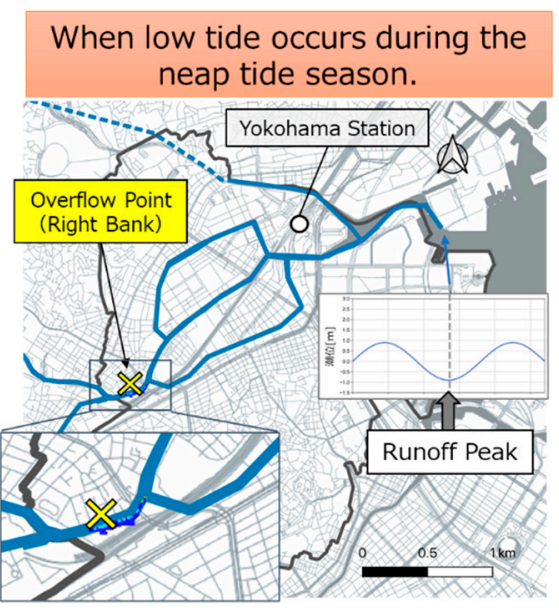

(b)

Figure 13. Comparison of the maximum and minimum inundation situations obtained through river water flooding analysis: (a) when high tide occurs during full tide in the spring tide season; and $(\mathbf{b})$ when low tide occurs during the neap tide season.

\subsection{Result of River Water/Inland Simultaneous Flooding Calculation}

When conducting the river water/inland simultaneous flooding calculation, a postulated case where $75 \mathrm{~mm} / \mathrm{h}$ rain fell continuously for one hour on the subject area was given as the rain condition. This is the rainfall that is said to occur in the subject area at a probability of once every 30 years. The real tide level measured during the arrival of Typhoon Lan in 2017 was used as the downstream end tide level. The calculation time was set to four hours from the start of the rainfall. Figure 14 shows the calculation result. Inundation caused by inland flooding occurred near Yokohama Station 20 min after the rainfall began. This flooding started with the overflow from the branches connected to the main line instead of an overflow from the main sewage line. After $50 \mathrm{~min}$, river water flooding occurred at the flooding point of the river and the inundation area continued to expand as the time passed. It was found that the flooding water gathered at a low altitude area as the time passed, and that the expansion of the inundation area stopped around $140 \mathrm{~min}$ after the start of the rain, and about $1 \mathrm{~h}$ after the rain had stopped.

The verification results of river water/inland simultaneous flooding calculation are summarized in Table 3.

Table 3. Verification results.

\begin{tabular}{ll}
\hline \multicolumn{1}{c}{ Verification } & \multicolumn{1}{c}{ Result } \\
\hline $\begin{array}{l}\text { The effect of high tide on river water flooding. } \\
\text { (From Section 4.1) }\end{array}$ & $\begin{array}{l}\text { (1) The location of the flooding changes. } \\
\text { (2) The maximum inundation height changes from } 3.02 \text { to } 3.85 \mathrm{~m} .\end{array}$ \\
\hline $\begin{array}{ll}\text { Differences in inundation onset time by river } & \text { (3) The area of the flooding changes from } 0.004 \text { to } 0.149 \mathrm{~km}^{2} .\end{array}$ \\
$\begin{array}{ll}\text { water/inland simultaneous flooding calculation. } & \text { (1) Inland flooding begins after } 20 \mathrm{~min} . \\
\text { (From Section 4.2) } & \text { (2) River water flooding begins after } 50 \text { min. } \\
& \text { (3) The difference between the time an inland flooding and a } \\
& \text { river water flooding begins is } 30 \text { min. }\end{array}$ \\
\hline
\end{tabular}




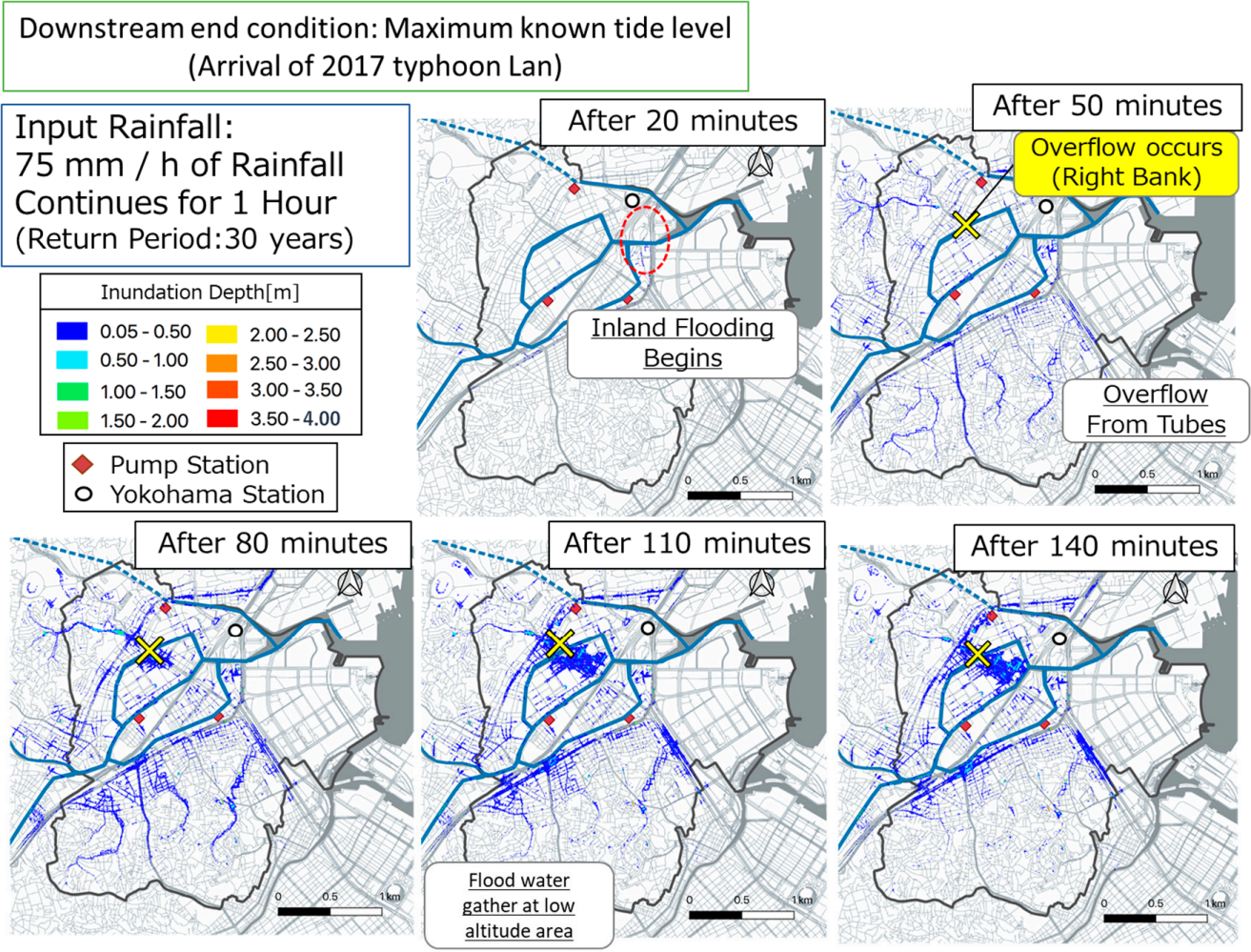

Figure 14. Inundation process obtained through the constructed river water and inland flooding analysis.

\subsection{Inundation Process during A Simultaneous Occurrence of River Water/Inland Flooding}

It was clarified in Section 4.2 that there is a time gap between the occurrence of river water flooding and inland flooding, and that inland flooding occurs first. Thus, the flooding process was analyzed by focusing on the chronological change of inundation depth at the point where it was deepest. Figure 15 shows the chronological change of inundation depth at the deepest point (indicated with the red dot). The inundation depth of the inland flooding started to increase approximately $40 \mathrm{~min}$ from the start of the calculation and reached its deepest inundation depth (about $0.2 \mathrm{~m}$ ) after approximately $70 \mathrm{~min}$. In contrast, the inundation depth of the river water flooding started to rapidly increase after about $90 \mathrm{~min}$ and its water level increased by some $0.6 \mathrm{~m}$ in approximately $20 \mathrm{~min}$. As a result, the $0.8 \mathrm{~m}$ inundation depth at this point was anticipated to be from the flooding of the inland and river water. Upon examination of the protocol for issuing evacuation information in Japan [34], it was found that it is in principle issued in response to river water levels and does not consider inland flooding. As inland flooding commonly starts with the overflow of, for instance, manholes, the expansion speed of floodwater is not very fast, although that depends on the inclination of the terrain. Thus, it is considered to have little effect on evacuation. However, if inland and river water flooding occur simultaneously, a situation where people cannot evacuate due to inland floodwater and then get caught in floodwater from subsequent river flooding could be envisaged. Especially in large cities, there are many underground and commercial facilities, and there is a high probability that inland floodwater flows in and inundates underground facilities. Moreover, with respect to the doors of buildings, it is understood that doors that open outwards can no longer be opened when the depth of inundation reaches $26 \mathrm{~cm}$, while doors that open inwards can no longer open when the depth of inundation reaches $47 \mathrm{~cm}$ [35]. Thus, there is also a possibility that one cannot evacuate a building when floodwater reaches certain depths. Furthermore, the flow speed and depth that would allow an adult male to walk safely through water is considered to be less than $1 \mathrm{~m} / \mathrm{s}$ when the water depth is no more than $0.4 \mathrm{~m}$ [35]. Thus, if a person does not immediately evacuate when inland flooding occurs, it is possible that $\mathrm{s} /$ he will lose his/her life from subsequent river flooding. In light of the factors 
discussed above, it can be inferred that in a large city, river water flooding may take place after the occurrence of inland flooding. Therefore, it can be said that unless the occurrence of inland flooding is predicted and evacuation information is issued at that point in time, a situation where subsequent evacuation would be difficult can be anticipated.
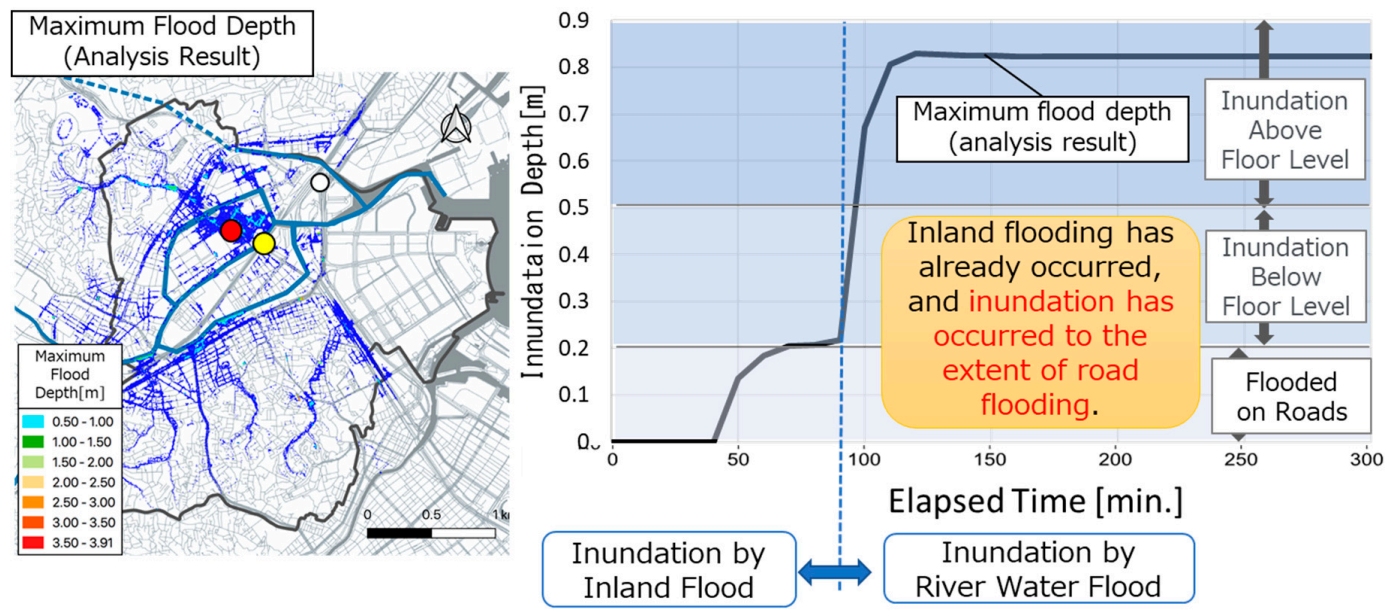

Figure 15. Chronology of inundation depth during the simultaneous occurrence of river water/inland flooding.

\section{Conclusions}

1) This study investigated the Katabira River, which is the tidal river of Yokohama City, one of the main large cities of Japan, to construct a simultaneous occurrence model of river water and inland flooding that incorporates the influence of high tide. Its accuracy was then examined and the flooding phenomena predicted in the subject area were analyzed. With the results of calculations, it was determined that the occurrence location of river water flooding differs depending on whether it is during the planned maximum tide level or during low tide, and that the inundation areas are also significantly different. From this, it can be stated that taking high tide into consideration is important when conducting flooding simulations of tidal rivers in large cities. Moreover, it was discovered that the tide level is influenced by atmospheric pressure, wind direction, and wind speed, and therefore improvement in prediction accuracy is directly linked to the results of flooding predictions.

2) It was discovered that at the Katabira River basin, inland flooding occurs first, followed by river water flooding, when they occur simultaneously. In addition, inundation by river water occurs extremely quickly, suggesting the possibility that unless one evacuates before the commencement of inland flooding, one may not be able to evacuate at all.

From these findings, it can be argued that it is urgent to revise the issuing protocol for evacuation information based on river water flooding, as has been practiced in Japan thus far, and to issue new protocols of evacuation information that also take inland flooding into account. In order to realize this, the development of a faster and easier calculation method for the simultaneous occurrence of river water and inland flooding that takes high tide into account is necessary, and we aim to improve on our method in the future.

Author Contributions: Conceptualization, N.K. and T.Y.; methodology, N.K.; software, N.K.; validation, N.K., T.Y.; formal analysis, N.K.; writing-original draft preparation, N.K.; writing-review and editing, T.Y.; and supervision, T.Y. All authors have read and agreed to the published version of the manuscript.

Funding: This research was supported by Unit for Research and Application Solution of Water-Related Disaster Science and Information of Research and Development Initiative (RDI), Chuo University.

Acknowledgments: We would like to thank City of Yokohama and Tokyu Construction Co., Ltd. for assisting with data collection.

Conflicts of Interest: The authors declare no conflict of interest. 


\section{References}

1. Wallemacq, P.; Herden, C.; House, R. The Human Cost of Natural Disasters 2015: A Global Perspective; Technical Report; Centre for Research on the Epidemiology of Disasters: Brussels, Belgium, 2015.

2. Stocker, T.F.; Qin, D.; Plattner, G.-K.; Tignor, M.; Allen, S.K.; Boschung, J.; Nauels, A.; Xia, Y.; Bex, V.; Midgley, P.M. Climate change 2013: The physical science basis. In Contribution of Working Group I to the Fifth Assessment Report of the Intergovernmental Panel on Climate Change; Cambridge University Press: Cambridge, UK, 2013; Volume 1535.

3. Technical Mapping Advisory Council (TMAC). Technical Mapping Advisory Council (TMAC) 2015 Annual Report Summary. Available online: https:/www.fema.gov/media-library-data/145495418644134ff688ee1abc00873df80c4d323a4df/TMAC_2015_Annual_Report_Summary.pdf (accessed on 19 April 2020).

4. European Environmental Agency (EEA). Mapping the Impacts of Natural Hazards and Technological Accidents in EUROPE-an Overview of the Last Decade. EEA Technical Report No13/2010. Available online: https://www.eea.europa.eu/publications/mapping-the-impacts-of-natural (accessed on 19 April 2020).

5. Water and Disaster Management Bureau, Ministry of Land, Infrastructure, Transport and Tourism. Flood Damage Statistical Study. Available online: https://www.mlit.go.jp/river/toukei_chousa/kasen/suigaitoukei/ index.html (accessed on 19 April 2020).

6. Jha, A.K.; Bloch, R.; Lamond, J. Cities and Flooding: A Guide to Integrated Urban Flood Risk Management for the 21th Century; World Bank: Washington, DC, USA, 2012.

7. Galloway, G.; Brody, S.; Reilly, A.; Highfield, W.E. The Growing Threat of Urban Flooding: A Natioanal Challenge; University of Maryland: Maryland, MD, USA; Texas A\&M University: Texas, TX, USA, 2018.

8. Hollis, G.E. The effects of urbanization on floods of different recurrence interval. Water Resour. Res. 1975, 8, 431-435. [CrossRef]

9. Morita, S.; Izumi, K. Quantitative Analysis, the Difference of Flood Runoff Depth Associated with Urbanization. Proc. Jpn. Conf. Hydraul. 1985, 29, 19-24.

10. Muis, S.; Güneralp, B.; Jongman, B.; Aerts, J.C.J.H.; Ward, P.J. Flood risk and adaptation strategies under climate change and urban expansion: A probabilistic analysis using global data. Sci. Total Environ. 2015, 538, 445-457. [CrossRef] [PubMed]

11. Mahmoud, H.M.; Gan, T.Y. Urbanization and climate change implications in flood risk management: Developing an efficient decision support system for flood susceptibility mapping. Sci. Total Environ. 2018, 636, 152-167. [CrossRef] [PubMed]

12. Wang, S.; McGrath, R.; Hanfin, J.; Lynch, P.; Semmler, T.; Nolan, P. The impact of climate change on storm surges over Irish waters. Ocean Model. 2008, 25, 83-94. [CrossRef]

13. Suzuki, T. Japans inundation risk map of storm surge under global warming and inundation damage function of coastal area. Annu. J. Civ. Eng. Ocean 2012, 68. [CrossRef]

14. Ye, S.; Li, H.-Y.; Leung, L.R.; Guo, J.; Ran, Q.; Demissie, Y.; Sivapalan, M. Understanding flood seasonality and its temporal shifts within the contiguous United States. J. Hydrometeorol. 2017, 18, 1997-2009. [CrossRef]

15. Wang, W.; Li, H.Y.; Leung, L.R.; Yigzaw, W.; Zhao, J.; Lu, H.; Deng, Z.; Demisie, Y.; Blöschl, G. Nonlinear filtering effects of reservoirs on flood frequency curves at the regional scale. Water Resour. Res. 2017, 53, 8277-8292. [CrossRef]

16. Milner, A.M.; Picken, J.L.; Klaar, M.J.; Robertson, A.L.; Clitherow, L.R.; Eagle, L.; Brown, L.E. River ecosystem resilience to extreme flood events. Ecol. Evol. 2018, 8, 8354-8363. [CrossRef] [PubMed]

17. Meteorological Agency. Yearly Occurrence of Rain with More than 50mm Hourly Rainfall in Japan (AMeDAS). Available online: https://www.data.jma.go.jp/cpdinfo/extreme/extreme_p.html (accessed on 19 April 2020).

18. Teng, F.; Shen, Q.; Huang, W.; Ginis, I.; Cai, Y. Characteristics of river flood and stom surge interactions in a tidal river in Rhode Island, USA. Procedia IUTAM 2017, 25, 60-64. [CrossRef]

19. Konishi, T.; Kinoshita, T. Studies on the River Invasion of the Storm Surges (II); Report of NRCDP; NIED: Ibaraki, Japan, 1985; pp. 13-42.

20. Yoneda, H.; Stoh, M.; Kawamura, I.; Yamaguchi, M.; Matsumoto, K.; Yamada, T. The risk assessment of the flood damage by inner and river water simultaneous flood analysis with uncertainty of rainfall and runoff analysis. J. Jpn. Soc. Civ. Eng. 2018. [CrossRef]

21. Sekine, M.; Kodama, K. Evaluation of inundation risk during heavy rain in Tokyo 23 wards and pre-flooding underpass. J. Jpn. Soc. Civ. Eng. 2018. [CrossRef] 
22. Pinheiro, J.P.; Lopes, C.L.; Ribeiro, A.S.; Sousa, M.C.; Dias, J.M. Tide-surge interaction in ria de aveiro lagoon and its influence in local inundation patterns. Cont. Shelf Res. 2020. [CrossRef]

23. Oliveira, H.A.; Fernandes, E.H.L.; Möller, O.O.; García-Rodríguez, F. Relationships between wind effect, hydrodynamics and water level in the world's largest coastal lagoonal system. Water 2019, 11, 2209. [CrossRef]

24. Ullman, D.S.; Ginis, I.; Huang, W.; Nowakowski, C.; Chen, X.; Stempel, P. Assessing the multiple impacts of extreme hurricanes in Southern New England, USA. Geosciences 2019, 9, 265. [CrossRef]

25. Cavallaro, L.; Iuppa, C.; Foti, E. Effect of partial use of venice flood barriers. J. Mar. Sci. Eng. 2017, 5, 58. [CrossRef]

26. Yokohama City Disaster Prevention Council. Yokohama City Disaster Prevention Plan, Chapter on Wind and Flood Disaster Measures, Yokohama 2020. Available online: https://www.city.yokohama.lg.jp/kurashi/ bousai-kyukyu-bohan/bousai-saigai/bosaikeikaku/shishin/keikaku/20140221173341.html (accessed on 19 April 2020).

27. Hanayama, M.; Sekimoto, T.; Shimizu, T.; Moriya, Y. Applicability of high tide deviation estimation equation that takes physical mechanism into account. Collect. Coast. Eng. Pap. 2000, 47, 206-210.

28. National Institute for Land and Infrastructure Management. Flood Laboratory, NILIM2. Urban Flooding Analysis Model Manual. 2012. Available online: http://www.nilim.go.jp/lab/rcg/newhp/seika.files/nilim/ download/manual.pdf (accessed on 19 April 2020).

29. Watanabe, A.; Sasada, T.; Watanabe, N.; Yamada, T. Theoretical derivation of synthesized rational formula. J. Jpn. Soc. Civ. Eng. 2012, 167. [CrossRef]

30. Public Works Research Institute. Flood Simulation manual (draft): Guide for simulation and verification of new model; Technical Report of PWRI, Ibaraki, Japan. 1996. Available online: https:/jglobal.jst.go.jp/detail? JGLOBAL_ID=200902187060084615 (accessed on 21 June 2020).

31. Watanabe, M.; Toyokuni, E. Urban catchment modeling and stormwater runoff simulations. J. Jpn. Soc. Civ. Eng. 1989, 8, 46-63.

32. Geospatial Information Authority of Japan. Base Map Information Download Service. Available online: https://fgd.gsi.go.jp/download/menu.php (accessed on 19 April 2020).

33. Hashino, M.; Kanda, T.; Kitazawa, M.; Yokoyama, S. Study on characteristics of concurrence of rainfall and storm surge associated with typhoon. J. JSCE 1985, 357, 141-148.

34. Cabinet Office (Disaster prevention section). Guideline for Evacuation Advice. Available online: http: //www.bousai.go.jp/oukyu/hinankankoku/pdf/guideline_kaitei.pdf (accessed on 19 April 2020).

35. Ministry of Land, Infrastructure, Transport and Tourism: Guideline for Anti-Flooding Measures in Underground Space. Available online: https:/www.mlit.go.jp/river/basic_info/jigyo_keikaku/saigai/tisiki/ chika/pdf/g-11_g-14.pdf (accessed on 19 April 2020). 